\title{
TDA/H - Análise documental sobre a produção do conceito
}

\author{
leda Maria Munhós Benedetti \\ Universidade Federal de Mato Grosso do Sul - MS \\ Alexandra Ayach Anache \\ Universidade Federal de Mato Grosso do Sul - MS
}

\begin{abstract}
Resumo
Este artigo apresenta resultados de uma pesquisa desenvolvida para fins de doutoramento pela UFMS, sobre temática do TDA/H. Traz a análise do processo de construção do conceito de TDA/H em suas diversas vertentes teóricas a partir do estudo da produção científica sobre o tema publicada entre os anos de 2003 e 2007 e posteriormente atualizada até 2013, nas principais revistas científicas do ramo. Demonstra a conceituação hegemônica sobre o transtorno e as vertentes críticas desse posicionamento teórico. Conclui que não há consenso nas pesquisas apresentadas e que as nuanças desta temática estão estreitamente ligadas ao processo de construção do conceito, ou seja, a metodologia e as bases epistemológicas utilizadas pelos pesquisadores que estudam o transtorno influenciam e definem posições, opções de terapêuticas, condutas éticas e até mesmo a convicção da existência desse transtorno.
\end{abstract}

Palavras-chave: TDA/H; medicalização da aprendizagem; fracasso escolar.

\section{TDA / H - Documentary analysis on the concept of roduction}

\begin{abstract}
In this article we present some of a PhD research developed at University of Mato Groso do Sul on ADD / H. We offer an analysis of the construction of the concept of ADD / $\mathrm{H}$ in its various theoretical perspectives from the study of scientific production around the topic, published between the years 2003 to 2007 and later updated by 2013 in major journals branch .Our work demonstrates the hegemonic conceptualization of the disorder and the critical aspects of this theoretical position. We conclude that there is no consensus in the research presented and the nuances of this issue is closely linked to the process of construction of the concept, that is, the methodology and epistemological bases, used by researchers who lecture about the disorder, will influence and define positions, therapeutic options, ethical conduct and influences even the conviction of the existence of this disorder.
\end{abstract}

Keywords: TDA/H; medicalization of learning; academic failure.

\section{TDA/H - Análisis documental sobre la produción del concepto}

\section{Resumen}

Este artículo presenta resultados de una investigación desarrollada para fines de doctoramiento por la UFMS, sobre temática del TDA/H. Trae el análisis del proceso de construcción del concepto de TDA/H en sus diversas vertientes teóricas a partir del estudio de la producción científica sobre el tema publicada entre los años de 2003 y 2007 y posteriormente actualizada hasta 2013, en las principales revistas científicas del ramo. Demuestra la conceptuación hegeménica sobre el trastorno y las vertientes críticas de ese posicionamiento teórico. Concluye que no hay consenso en las investigaciones presentadas y que las matices de esta temática están extremamente atadas al proceso de construcción del concepto, o sea, la metodología y las bases epistemológicas utilizadas por los investigadores que estudian la perturbación influencian y definen posiciones, opciones de terapéuticas, conductas éticas e incluso la convicción de la existencia de esa perturbación.

Palavras-chave: TDA/H; medicalização da aprendizagem; fracasso escolar. 


\section{Introdução}

Essa pesquisa aponta o uso abusivo do metilfenidato, com aumento do uso desse medicamento da ordem de $940 \%$ nos anos de 2005 e 2006, com um milhão de caixas vendidas neste período, segundo Benedetti (2009, p. 198), além do uso permanentemente crescente deste medicamento. Em 2013, dados da Agência Nacional de Vigilância Sanitária (ANVISA) confirmam a continuidade do crescimento do uso desse medicamento: "(...) entre 2009 a 2011 a venda desses remédios aumentou 75\%”. Em contrapartida vários trabalhos sobre o tema em referência - como Souza (2011), Patto (1999), Collares, \& Moysés (1992) - discutem os dilemas deste transtorno no meio escolar. Discorreremos sobre os posicionamentos desses autores ao longo deste trabalho tendo como foco os dilemas conceituais da literatura sobre o TDA/H.

\section{Método}

Realizamos pesquisas sobre as produções acadêmicas dos trabalhos produzidos sobre o tema TDA/H no período de 1999 a 2013. Para tanto, foram definidos como fontes de pesquisa: os livros especializados no tema localizados na internet aberta, através de sites de pesquisa; ainda através da internet, foram acessados os fóruns de debate sobre o tema e o portal de periódicos e teses da Coordenação de Aperfeiçoamento de Pessoal de Nível Superior (CAPES). Tomamos também como fonte secundária matérias televisivas sobre a temática TDA/H, buscando reportagens veiculadas em rede nacional pelo maior canal de TV aberta do país, a Rede Globo.

Buscamos trazer as pesquisas dos diversos autores que discutem a temática em referência, entre eles Vasconcelos e cols. (2007), Legnani (2008) e Argolo (2004), apresentando aqui as discussões teóricas que se estabeleceram sobre o tema.

A escolha das revistas teve como critério 0 ranking Qualis, desenvolvido pela CAPES. Foram selecionadas as que possuem Qualis entre A1 e B2.

As revistas que apresentavam maior número de artigos sobre o tema foram: Caderno CEDES (1999-2009), Educação e Sociedade (1999-2009), Revista Brasileira de Educação (1999-2007), Revista Brasileira de Psiquiatria (1999-2007), Revista de Psiquiatria Clínica (1999-2007) e Periódicos Eletrônicos em Psicologia (1999-2011).

Do mesmo modo, escolheu-se o portal da CAPES por este conter em seus arquivos as teses, dissertações e os principais resultados de pesquisas desenvolvidas no Brasil na atualidade.

Assim, a partir das palavras-chave TDAH, Hiperatividade e Déficit de Atenção, foram pesquisados 212 textos, dos quais 128 (60\%) eram artigos 31 (15\%) eram teses e três eram dissertações e 50 (25\%) eram resumos de teses.
Estes trabalhos foram divididos em eixos temáticos por nós classificados em três eixos: a vertente hegemônica, a psicanalítica e a histórico-cultural.

\section{Discussões}

O referencial teórico e metodológico das pesquisas orienta o pesquisador sobre a construção das informações que irá produzir a respeito do assunto pesquisado, ou seja, sobre o posicionamento que ele usou para explicar o problema em estudo. Como este artigo é essencialmente um estado da arte sobre o tema, cabe-nos apenas apontar as diferentes vertentes dos artigos levantados, sem entrar no mérito de sua pertinência ou não.

O principal referencial teórico que sustenta os trabaIhos de pesquisa tem sido o Positivismo, que consiste na observação dos fenômenos, opondo-se ao racionalismo e ao idealismo, que promovem o primado da experiência sensível, a única capaz de produzir a partir dos dados concretos (positivos) a verdadeira ciência (na concepção positivista), sem qualquer atributo teológico ou metafísico, subordinando a imaginação à observação e tomando como base apenas o mundo físico ou material. O Positivismo nega à ciência qualquer possibilidade de investigar a causa dos fenômenos naturais e sociais, considerando este tipo de pesquisa inútil e inacessível, voltando-se para a descoberta e o estudo das leis.

Setenta e seis por cento (76\%) da produção pesquisada norteiam-se por essa abordagem teórica e vinte e quatro por cento (24\%) dedicam-se a outras vertentes ou à crítica a esta abordagem, indicando também que o desenvolvimento do tema é determinado, fundamentalmente, pela escolha da metodologia das pesquisas.

A análise dos artigos, resumos e teses nos gráficos já apresentados indica que duas grandes tendências se alternam na busca da descrição e compreensão do TDA/H (Transtorno de Déficit de Atenção com ou sem Hiperatividade). A corrente positivista, fiel à sua concepção de ser humano e aos seus pressupostos metodológicos, propõe-se a descrever, medir, quantificar, correlacionar orgânica e quimicamente, conceituar e definir a prevalência em uma amostra da população, utilizando elementos do quadro diagnóstico descrito relacionados a elementos genéticos e biológicos, enquanto a do racionalismo e do idealismo se organizam em torno da crítica ao modo e à estrutura conceitual de onde se originam conceitos como o referido transtorno e à forma como este vem sendo descrito e veiculado pela referida corrente. Entre os grupos que criticam a concepção de TDA/H nos moldes positivistas encontra-se uma parcela que busca uma análise ampla do conceito, contextualizando a questão historicamente, considerando elementos emocionais, temporais, históricos e sociais, opondo-se às concepções descritivas, baseadas na apresentação de processos externamente observáveis e classificatórios.

No conjunto das produções acadêmicas encontramos as primeiras referências aos transtornos hipercinéticos 
na literatura médica em meados do século XIX. Convenientemente, sua nomenclatura sofre alterações contínuas. A substituição do termo lesão por disfunção ocorreu por reconhecer-se que as alterações características da síndrome relacionam-se mais a disfunções em vias nervosas do que, propriamente, a lesões nessas vias.

A publicação da DSM-III, em 1980, revolucionou a visão médica acerca do referido transtorno, introduzindo grandes mudanças: a) abandono da inclusão da etiologia na definição e na terminologia em favor de critérios operacionais fenomenológicos; b) a possibilidade de uma vertente do quadro sem hiperatividade, enfatizando ser a desatenção o principal sintoma; e c) a possibilidade de uma forma adulta, chamada de Tipo Residual.

Collares \& Moysés (1992) assinalaram que as mudanças nas denominações ocorreram em função do descrédito com que tais distúrbios passaram a ser encarados, por não ter havido comprovações nas pesquisas experimentais que validassem a existência de uma lesão no aparato orgânico do cérebro, ou mesmo de uma disfunção no funcionamento cerebral.

De qualquer modo, a troca na denominação não trouxe mudanças na concepção ou na postura crítica dos pesquisadores em relação a um ponto crucial dessas entidades clínicas. Essa credibilidade iniciou-se na década de 80, na edição do DSM III (Manual Diagnóstico e Estatístico de Transtornos Mentais), quando a Academia Americana de Psiquiatria propôs a separação entre as perturbações por Déficit de Atenção e Hiperatividade e os Distúrbios de Aprendizagem, orientação que posteriormente seia incorporada pelo DSM IV.

De acordo com o DSM-IV-TR (American Psychiatric Association), o quadro se caracteriza por três grupos de sintomas, cuja predominância vai definir o subtipo da doença: o combinado, o predominantemente desatento e o predominantemente hiperativo/impulsivo. O predominantemente desatento é o subtipo mais comum, porém menos diagnosticado, uma vez que este transtorno é mais tolerado socialmente.

Para Legnaniet (2006), os elementos clínicos dessa disfunção acometeram os campos da atenção e concentração. Para efeito de diagnóstico, esta característica deve comparecer desde os primeiros anos de vida. Os outros comportamentos disfuncionais - como, por exemplo, a inabilidade para se organizar e seguir regras e instruções -, assim como as dificuldades escolares, são derivados da própria disfunção; por sua vez, a hiperatividade propriamente dita não apareceria em todos os casos e caracterizar-se-ia por uma movimentação corporal incessante, que traria à criança dificuldades em realizar quaisquer tarefas que requeiram poucos movimentos corporais. Por fim, a impulsividade, que se apresentaria apenas em alguns casos e que se traduziria na incapacidade da criança de responder às demandas do outro e do ambiente de forma pertinente, seja pela dificuldade em estabelecer uma comunicação dialógica efetiva, seja por comportamentos que demonstrem embaraçamentos na esfera do cumprimento de regras e normas.
Dentro da visão descritiva do quadro, o Código Internacional de Doenças, décima revisão - CID-10, faz o seguinte enquadramento para distúrbios de atenção:

F90.0 - Distúrbios da atividade e da atenção: grupo de transtornos caracterizados por início precoce (habitualmente durante os cinco primeiros anos de vida), falta de perseverança nas atividades que exigem um envolvimento cognitivo, e uma tendência a passar de uma atividade a outra sem acabar nenhuma, associadas a uma atividade global desorganizada, incoordenada e excessiva. Os transtornos podem se acompanhar de outras anomalias. As crianças hipercinéticas são frequentemente imprudentes e impulsivas, sujeitas a acidentes e incorrem em problemas disciplinares mais por infrações não premeditadas de regras que por desafio deliberado. Suas relações com os adultos são frequentemente marcadas por uma ausência de inibição social, com falta de cautela e reserva normais. São impopulares com as outras crianças e podem se tornar isoladas socialmente. Estes transtornos se acompanham frequentemente de um déficit cognitivo e de um retardo específico do desenvolvimento da motricidadee dalinguagem. A s complicações secundárias incluem um comportamento dissocial e uma perda de autoestima. Síndrome de déficit da atenção com hiperatividade Transtorno de déficit da atenção com hiperatividade Transtorno de hiperatividade e déficit da atenção. Exclui: transtorno hipercinético associado a transtorno de conduta (Organização Mundial da Saúde, 1993, p. 9).

Os critérios do Manual DSM-IV preconizam que o diagnóstico seja obtido quando o paciente atenda a pelo menos seis dos nove critérios abaixo citados, de um ou de ambos os domínios da síndrome (hiperatividade/impulsividade e desatenção), em pelo menos dois locais de avaliação distintos, como por exemplo, a residência do suposto paciente e a escola.

Vasconcelos e cols. (2005) afirmam que o transtorno de déficit de atenção/hiperatividade é o distúrbio do neurodesenvolvimento mais comum na infância. Nesta concepção o TDA/H tem o seu diagnóstico clínico apoiado no uso de testes. Existem variações do quadro clínico, entre elas as comportamentais, as cognitivas e as sociais. Outras comorbidades neuropsiquiátricas - como distúrbios disruptivos, depressão, dificuldade de aprendizado e ansiedade - são associadas com a doença crônica. O tratamento farmacológico é feito, em primeira escolha, com metilfenidato, porém existem variações de acordo com a produção sintomática e comorbidades, sendo ainda indicada a intervenção integrada dos psicofármacos com intervenção na escola e terapia comportamental e cognitiva. Distúrbios de delinquência e conduta são prevenidos com o tratamento da criança ou adolescente com o transtorno.

A genética é tida como relevante na determinação ou não de TDA/H no indivíduo; a hereditariedade é aceitável e a influência ambiental também faz parte desse processo. Para a corrente fundamentada na concepção hegemônica 
de ciência, o cérebro e seu funcionamento químico são o lócus, o endereço do TDA/H. Embora a base genética e o fundo orgânico, para esta corrente, sejam dados apriorísticos que fundamentam toda a base conceitual do transtorno, os critérios para a afirmação de sua existência são clínicos, não havendo ainda evidências comprovadas por exames ou outros recursos materiais.

O quadro apresenta um grande número de comorbidades de diversas ordens, cabendo perfis de indivíduos bastante diferentes dentro do mesmo quadro. Além disso, algumas contradições são encontradas na análise do TDA/H, uma vez que o quadro engloba tantos componentes que este se confunde com outros.

A metodologia de tratamento para o $\mathrm{TDA} / \mathrm{H}$, nesta abordagem, segue os padrões da ciência positivista. Deste modo, a busca de uma correlação entre comportamentos apresentados, sintomas e causas orgânicas, caminha para a busca de respostas através da medicalização. Argollo (2003) preconiza que a intervenção terapêutica seja realizada com psicoterapia e fármacos. A intervenção psicossocial deve englobar a educação dos pais sobre o transtorno e treinamento de estratégias comportamentais para eles lidarem com os seus filhos. Do mesmo modo, os professores devem receber orientações sobre como organizar uma sala de aula para crianças com TDA/H. Como poucos alunos, rotinas diárias e previsíveis, poderão ajudar no controle emocional da criança. O controle que padroniza o comportamento do indivíduo não leva em consideração critérios subjetivos inerentes a cada sujeito. A indicação de tratamento para o quadro, dentro da abordagem analisada, por fim, inclui medicação, bem como terapia de base comportamental e cognitiva. As demais linhas e abordagens não são indicadas dentro deste modelo. Rohde e Halpern (2004) entendem que o metilfenidato é a medicação com maior comprovação de eficácia. Cabe ressaltar que Schmitz, Polanczyk e Rohde (2007) apontam o potencial conflito de interesses, pois:

O Programa de Transtornos de Déficit de Atenção/ Hiperatividade (PRODAH) recebe suporte de pesquisa das seguintes companhias farmacêuticas: Bristol-Myers Squibb, Eli-Lilly, Janssen-Cilag e Novartis. O Prof. Rohde é palestrante ou consultor das companhias acima referidas e é integrante do conselho consultivo da Eli Lilly (Schmitz, Polanczyk, \& Rohde, 2007).

A concepção de que o quadro de TDA/H apresentou uma origem neurológica e ligada a um desequilíbrio químico oferece o suporte para a indicação do uso de medicamento.

Argollo (2003) descreveu os benefícios do uso do metilfenidato em qualquer idade, no tratamento do TDA/H. Esse medicamento é comercializado com o nome de Ritalina $\AA$, que, segundo o autor, apresenta efeito de curta duração. No caso da Ritalina $\AA$, podem ser indicadas até três doses ao dia. O metilfenidato também apresenta o nome comercial: Conserta $\AA$; Barkley, Mcmurray e Dupaul (1990) indicam que o metilfenidato apresenta uma série de efeitos colaterais. Apesar do aumento nas vendas dessa medica- ção, estes pesquisadores acreditam que o transtorno ainda esteja subdiagonosticado.

Contrapondo-se aos que querem maior controle no uso das medicações e sugerem políticas mais criteriosas de fiscalização e controle desses usos, Carlini, Nappo, Nogueira e Naylor (2003) defendem, mesmo diante do aumento do consumo do metilfenidato, que se a amenize a regulamentação para se prescrever a medicação.

Um vez feita a apresentação dos conceitos fundamentais sobre TDA/H defendidos pela corrente hegemônica, neste trabalho nos dedicaremos, a partir deste momento, a apresentar a visão dos autores que apresentam contrapontos à vertente apresentada acima.

Em um artigo clássico da área de educação, "A História não contada dos distúrbios de aprendizagem", Colares e Moysés (1992, p. 31) chamam a atenção para a etimologia dos distúrbios da aprendizagem, definindo-a como uma anormalidade patológica por alteração violenta da ordem natural, situando a problemática, já de início, em quem aprende, ficando implícito que, na construção diagnóstica, excluem-se os fatores ligados ao processo ensino-aprendizagem.

Para as autoras, os distúrbios de aprendizagem são uma construção do pensamento médico; surgem como entidades nosológicas e persistem como doenças neurológicas. Elas denunciam um equívoco lógico que assim pode ser formulado: um quadro orgânico, como um traumatismo cerebral, pode causar um problema de aprendizagem, e isso é fato e é correto; o equívoco reside em entendermos que, se uma doença neurológica pode comprometer o domínio da aprendizagem, todos os problemas de aprendizagem, em geral, deveriam a ser compreendidos como doenças neurológicas.

Criticando a base biologicista, as autoras descrevem o surgimento, no ano de 1957, do conceito da Síndrome Hipercinética ou Hiperatividade, como entidade clínica tratável, apresentando assim os primórdios conceituais do TDA/H. Os primórdios da teoria fisiopatológica são assim apresentados pelas autoras:

A partir da administração experimental de calmantes e estimulantes do sistema nervoso central (anfetaminas) a crianças com distúrbios de comportamento - em uma das experiências mais antiéticas na história da medicina - Bradley (1973) relatou a melhora da hiperatividade, da agressividade e da aprendizagem, em padrão constante e mantido, com o uso de anfetaminas. [...] Postulou-se um defeito da substancia Reticular Ativadora Ascendente (SRAA), espécie de "filtro" que, sob controle voluntário, determina os estímulos que chegarão ao córtex cerebral, tornandose conscientes e os que serão resolvidos em estruturas subcorticais. [...] Localizar nessa área um pretenso defeito garantiu um novo status a esse campo teórico (Collares, \& Moysés, 1992, p. 37).

Essa hipótese explicativa, até hoje sem confirmação, passou a ser apresentada como uma teoria científica e se 
consagrou, em 1962, no mesmo congresso em que se criou a expressão Disfunção Cerebral Mínima.

Em 1962, em simpósio internacional realizado em Oxford, com a finalidade de estudar a Lesão Cerebral Mínima, os grupos de pesquisa presentes, empregando todos os métodos de investigação do cérebro disponíveis, não conseguiram detectar nenhuma lesão. Sobre este fato, prosseguem Colares e Moysés (1992, p. 37): "Neste momento, os pesquisadores envolvidos reconheceram estar errados, porém sem questionar o ponto crucial de sua postura medicalizante. Reconhecem não haver lesão e proclamam a existência de uma disfunção". Essa doença foi, então, denominada de Disfunção Cerebral Mínima (DCM). As manifestações clínicas dessa doença, se tida como orgânica, seriam a hiperatividade, os distúrbios de comportamento e a agressividade, em qualquer incidência com qualquer combinação. Aqui começa a ciranda de siglas utilizadas para dissimular a evidência da não comprovação de um dado tido como científico.

A Disfunção Cerebral Mínima (DCM) surge, então, da impossibilidade de se comprovar a anormalidade biológica, tendo-se como saída a possibilidade de presumir uma disfunção que seria uma alteração funcional sem correspondência anatômica.

Foi no meio social que as autoras encontraram justificativas para a aceitação, na década de 1960, do que intitularam biologização ou atribuição de explicações biológicas a problemas da escola e sociedade. No contexto então vigente, os valores da sociedade americana eram contestados por jovens e minorias, demandando reformas nas instituições sociais, entre elas a escola. Em resposta a essa tensão, ocorreu uma biologização das questões sociais, buscando-se demonstrar que os diferentes papéis se devem a diferenças biológicas. Os argumentos passaram a basear-se no tamanho do cérebro, nas medidas de coeficiente de inteligência, etc. $O$ que se pretende, assim, é que a situação e os destinos de indivíduos e grupos possam ser explicados e reduzidos a características individuais. Neste momento surgem as entidades que se propõem a estudar a DCM: grupos de ajuda, livros, congressos, etc.

Vemos aqui a raiz do reducionismo e da culpabilização do sujeito que hoje encontramos nas práticas assumidas em nome do TDA/H. Nos dois casos, TDA/H e DCM, as hipóteses são tratadas como verdades, tornam-se crenças e se perpetuam, assim como as indicações de tratamentos medicamentosos e multidisciplinares, com diversos profissionais envolvidos.

Existe um mercado estruturado em torno de um diagnóstico, o TDA/H, cuja existência a ciência nunca conseguiu de fato demonstrar, mas que, de modo sui generis, a corrente hegemônica apregoa que existe e espera que seus oponentes provem que ela não existe. Afirmam Colares e Moysés (1992, p. 41):

Começa se a desvendar que se está lidando com um mercado de trabalho economicamente atraente, em expansão. Tão atrativo, que houve o surgimento de novas profissões baseadas nesta concepção do processo ensino aprendizagem, como a psicopedagogia. [...] Porém, os interesses econômicos não se restringem a isso, são muito maiores. Lida-se com a indústria farmacêutica. Drogas como a ritalina (methylfenidate, estimulante do sistema nervoso central) e nootropil (piracetam) são usadas praticamente apenas para essas "doenças".

O TDA/H seguiu um caminho idêntico ao de seu antecessor, a DCM. Para Lefévre (1986), esse diagnóstico passou para o conhecimento leigo e tornou-se frequente. $O$ autor aponta como causa dessa popularização da referida patologia o fato de ser mais cômodo para a escola atribuir ao aluno a culpa pelo fracasso do que rever critérios pedagógicos. Acrescentamos aqui o fato de também para a família ser mais cômodo reduzir a própria responsabilidade no que tange à disciplina e à dinâmica familiar, responsabilizando a criança ou repassando essa responsabilidade ao médico. Diante destas questões, ainda nos intriga um fato: a existência precoce da terapêutica medicamentosa, descoberta cerca de 40 anos antes da definição da doença.

Pesquisas apresentam agravantes para o uso abusivo de medicamentos anabolizantes na infância:

O seguimento dessas crianças revela, na adolescência, índices de comportamento delinquente e uso abusivo de drogas muito maiores do que na população geral da mesma faixa etária. Nada espantoso, pois se foram iatrogenicamente viciadas em anfetaminas ou outros estimulantes do sistema nervoso central, reconhecidamente um dos medicamentos que mais provoca dependência física e psíquica. Infelizmente, a conclusão dos autores é de que esses fatos confirmam seu diagnóstico inicial, isto é, as crianças realmente tinham um "defeito" (Hechtman, 1984 p. 415).

Fiori (2005) assim se pronuncia sobre o assunto:

É inquietante o número crescente de diagnósticos infantis, principalmente o que chamamos de Transtorno do Déficit de Atenção e Hiperatividade. Podemos dizer que este diagnóstico tem se alastrado de forma generalizada e implica, entre outras coisas, a medicalização das crianças que são nomeadas por ele. Este artigo traz alguns aspectos para a reflexão em torno do fenômeno contemporâneo da medicalização e seus desdobramentos na infância. Procura ressaltar como a produção de diagnósticos está atrelada ao uso de novas tecnologias do corpo e tem atravessado o espaço escolar, sem que seus profissionais tenham tempo e ferramentas teóricas adequadas para a sua abordagem e compreensão. A prática da medicalização infantil faz parte de um discurso biológico presente nas ciências da saúde e consolidado pelo saber médico, discurso esse que tem atravessado a instituição escolar, o nosso dia-a-dia, a forma como nos relacionamos e aprendemos, ou seja, construído novos paradigmas subjetivos. Deparamo-nos aqui com uma pergunta: por que medicalizar-se tornou mais uma urgência contemporânea? (Fiori, 2005). 
Legnani (2008) analisou criticamente a produção discursiva médica afirmando que a descrição médica hegemônica de TDA/H e a concepção de adoecimento que advém dessa sigla diagnóstica servem hoje de justificativa para se eclipsar o sujeito e os aspectos intersubjetivos responsáveis pela constituição e/ou cristalização de suas eventuais dificuldades. O discurso da ciência separa o sujeito de sua verdade e o aliena na certeza imaginária do conhecimento científico, submetendo-o aos saberes da hora.

Com base na proposta da análise documental sobre a produção do conceito, apresentamos agora outra concepção, diferente da hegemônica apresentada até agora, colocando aqui algumas ideias na vertente psicodinâmica a respeito do TDA/H.

O desenvolvimento da criança e seu modo de pensar, aprender, agir e até de adoecer, são influenciados não apenas pela genética, mas também por um conjunto de fatores históricos, sociais, emocionais e genéticos, como afirmam Costa (2006) e Kehl (2002). A concepção ética contemporânea que perpassa os modos de educação desse novo sujeito influencia a aprendizagem e a apresentação de seus resultados. O brincar ou o novo brincar é um fator a ser analisado.

As concepções psicodinâmicas valem-se da teoria psicanalítica como fundamento e entre os autores desta linha situam-se Costa (2006) e Kehl (2002), que referenciam este trabalho. No pensamento desses autores encontramos a crítica às terapias medicamentosas e às técnicas de autoajuda, tão indicadas pela corrente hegemônica para o tratamento do TDA/H. As referidas técnicas baseiam-se no pressuposto de que o psiquismo pode servir às finalidades de um eu soberano, pragmático, feliz, ajustado às aspirações dos membros da cultura do individualismo e do narcisismo, libertando o homem moderno dos incômodos efeitos do inconsciente. Para a teoria psicodinâmica o inconsciente é um pressuposto que não pode simplesmente ser abolido.

Nos textos fundamentados na teoria psicodinâmica, encontramos a concepção de que o TDA/H é um quadro sintomático que predomina no século presente, assim como a histeria predominou no final do século XIX e a depressão no século XX. Para esta vertente, o sujeito contemporâneo delega aos médicos e remédios o dever de arcar com as responsabilidades de trabalhar com a angústia, eliminando a inquietação vivenciada, ao invés de elaborá-la. Souza (2004, p. 129) afirma:

A preponderância, nos meios educacionais, de relações marcadas pela hierarquização; a atribuição ao outro de um lugar de desqualificação; a demanda por "receitas" para responder às vicissitudes enfrentadas na escolarização como as dificuldades no processo de ensino-aprendizagem, a presença da violência nas escolas, entre outras.

Pela adesão incondicional às teorias e métodos que adotam concepções de sujeito e do ensino-aprendizagem baseadas em modelos definidos a priori, todos esses aspectos podem dizer respeito às subjetividades conformadas por uma representação identitária rígida, as quais não toleram o contato com a angústia gerada pelo não saber e pelos limites do saber sobre si próprio, sobre o mundo social e o mundo natural.

Para Kehl (2002), a produção de sentido reside na coletividade. A cultura e toda a produção de significados caminham juntas, e as experiências de vida revelam-se entre o singular e o coletivo, que é posto como a inscrição simbólica do ser na cultura em que vive. Para a autora, é ingênuo pensar que podemos criar sintomas sem cultura. Não nascemos sendo, nós somos aquilo em que nos tornamos, e, salvo exceção, nós nos tornamos o que a cultura permite que venhamos a nos tornar.

Quando os sentidos dados pela tradição, pelas religiões e pela transmissão familiar deixam de fazer sentido, o vazio deixado por estes suscita preenchimento, e a alternativa medicamentosa insere-se como prótese, ocupando o lugar da elaboração subjetiva dos elementos.

Ainda para Kehl (2007), o que ocorre na sociedade contemporânea é que a palavra de ordem que organiza nossa sociedade dita de consumo (onde todos são chamados, mas poucos os escolhidos) é: "Você pode; você merece. Não há limites para você, cliente especial". O apelo ao narcisismo mais infantil visa a mobilizar apenas a vontade de comprar objetos, não impede que o narcisismo e a infantilidade governem a atitude de cada um diante de seus semelhantes, - principalmente quando o tal semelhante faz obstáculo ao imperativo do gozo. Assim o TDA/H se apresenta como uma rica metáfora para expressão simbólica e subjetiva desse mundo externo em transformação e desse mundo interno que não se consegue representar de outro modo senão com perda da atenção ou com hiperatividade.

\section{Considerações finais}

O objetivo central deste artigo consistiu em verificar o sentido das diferentes abordagens do TDA/H presentes na literatura científica e paracientífica.

A análise das diferentes vertentes que discorrem sobre o TDA/H nos permite afirmar que não há consenso sobre o tema e que os diversos posicionamentos a respeito geram diferentes propostas de entendimento e procedimentos indicados para o trabalho com os que apresentam o referido transtorno.

A análise do processo de construção do conceito (bases filosóficas e epistemológicas) determina as conclusões dos diversos pesquisadores e seus diferentes posicionamentos quanto a essa problemática. Os dados aqui expostos nos permitem afirmar que o TDA/H é um conceito polêmico, determinado pelos métodos de pesquisa que fundamentam as proposições sobre o tema.

Evidenciamos, a priori, dois eixos de análise: a) o TDA/H concebido nos moldes positivistas e constituído por concepções descritivas baseadas na apresentação de processos externamente observáveis e classificatórios; b) uma compreensão psicodinâmica que busca uma análise ampla 
do conceito, contextualizando a questão historicamente e considerando elementos emocionais, temporais, históricos e sociais.

Por outro lado, a conceituação hegemônica sobre este transtorno e as vertentes críticas demonstram que não há consenso nas pesquisas e que os diversos apontamentos acerca desta temática estão estritamente ligados ao processo de construção do conceito. As mudanças nas denominações ocorreram em função do descrédito com que tais distúrbios passaram a ser encarados, por "não ter havido comprovações nas pesquisas experimentais que validassem a existência de uma lesão no aparato orgânico do cérebro ou mesmo de uma disfunção no funcionamento cerebral" (Collares, \& Moysés, 1992).

Por conta da midiatização do TDA/H, percebemos uma popularização da referida patologia, pois para a escola é mais cômodo atribuir ao aluno a culpa pelo fracasso do que rever critérios pedagógicos, e para a família é mais cômodo porque reduz a disciplina e a dinâmica familiar, responsabilizando a criança ou repassando esta responsabilidade ao médico.

Desta forma, vários são os olhares que recortam a discussão sobre o TDA/H. Intrigam-nos as concepções críticas dos pesquisadores e a impossibilidade de comprovarem uma anormalidade que justifique a inclusão dos referidos quadros como patologias orgânicas, pois ocorreu uma terapêutica medicamentosa, descoberta cerca de 40 anos antes da definição da doença.

Salientamos as dificuldades em lidar com este tema e a invasão dos discursos médicos que tutelam a família e a escola. Precisamos estar atentos para que não ocorra uma psicopatologização excessiva, de modo que as taxonomias imperativas reduzam a criança a um ser comportado, bonzinho, quietinho. O achatamento dos desejos, da condição arredia que é própria da infância, pode conduzir nossos pupilos a uma sociedade normopática, onde a ausência de profundidade demarca uma condição hegemônica favorecendo ao biopoder o fortalecimento dos dispositivos de controle. Assim, se a produção do conceito a partir da análise documental nos aponta para caminhos um tanto díspares, onde fundamentos filosóficos e epistemológicos demarcam posicionamentos, nossa função enquanto intelectuais é defender a ética, a liberdade, e abrir caminhos para uma sociedade menos amordaçada.

\section{Referências}

Agência nacional de vigilância sanitária (Anvisa). (2013). Estudo aponta crescimento no consumo de metilfenidato. Recuperado: 24 mar. 2013. Disponível:

Argollo, N. (2003). Transtornos do déficit de atenção com hiperatividade: aspectos neurológicos. Psicologia Escolar e Educacional, Campinas, v. 7, n. 2, 2003. Recuperado: 27 jan. 2007. Disponível: http://scielo.bvs-psi.org.br/scielo.php?script=sci_arttex t\&pid=S1413-85572003000200010\& Ing=es\&nrm=is\&tlng=pt.
Barkley, R. A.. Mcmurray, M. B., \& Dupaul, G. J. (1990). Comprehensive evaluation of attention deficit disorder with and without hyperactivity as defined by research criteria. Journal of Abnormal Child Psychology, 58, 775-798.

Benedetti, I. (2009). A Produção do TDA/H: Transtorno de défict de atenção com ou sem hiperatividade. São Paulo: Scortecci.

Carlini, E. A., Nappo, S. A., Nogueira, V., \& Naylor, F. G. M. (2003). Metilfenidato: influência da notificação de receita A (cor amarela) sobre a prática de prescrição por médicos brasileiros. Revista de Psiquiatria Clínica, São Paulo, v. 30, n. 1, 2003. Recuperado: 02 mar. 2007. Disponível: http://www.scielo.br/scielo.php?script=sci_ arttext $\&$ pid=S0101-60832003000100002\&lng=pt\&nrm=iso.

Organização Mundial de Saúde. (1993). Classificação Estatística Internacional de Doenças e Problemas Relacionados à Saúde (CID). Recuperado: 19 jan. 2007. Disponível: http://www.datasus. gov.br/cid10/webhelp/cid10.htm.

Collares, C., \& Moysés, M. (1992). A história não contada dos problemas de aprendizagem. Caderno CEDES, n. 28.

Costa, J. (2006). A subjetividade e a diferença. Portal Brasileiro de Filosofia. Recuperado: 10 fev. 2007. Disponível: http://www. filosofia.pro.br/modules.php?name=News\&file=article\&sid=15.

Fiore, M.A. (2005). Medicalização do corpo na infância- Considerações acerca do Transtorno do Déficit de Atenção e Hiperatividade, Mnemosine, 1, 365-380.

Hechtman, L., Weiss, G., \& Perlman, T. (1984). Hyperactiver as young adults: past and current substance abuse and antisocial behavior. Am. J. Orthopsychiatry, 54 p.415.

Kehl, M. (2002). Existe a Função Fraterna? Em Kehl, M. R (Org.). Função Fraterna. Rio de Janeiro: Relume Dumará.

Kehl, M. R. (2004). Televisão e violência do imaginário. Em Bucci, E. \& Kehl, M. R. Rita. Videologias: ensaios sobre a televisão .(pp.87106 ). São Paulo: Bomtempo.

Legnani, V N., Andrade, M. F, Cairus, R. C. R., Kahn, C. T., Silva, E. A. S., \& Silva, E. A. (2006). Impasses na construção da noção de alteridade nos processos de subjetivação das crianças com o diagnóstico de transtorno de déficit de atenção e hiperatividade (TDA/H). Colóquio do LEPSI IP/FE-USP, 5., São Paulo. Recuperado: 20 jan. 2007. Disponível: http://www.proceedings. scielo.br/scielo.php?script=sci_arttext\&pid=MSC00000000320060 00100059\&lng=en\&nrm=abn.

Legnani, V. N., \& Almeida, S. F. C. (2008). A construção diagnóstica de Transtorno de Déficit de Atenção/Hiperatividade: uma discussão crítica. Arquivos Brasileiros de Psicologia, 60(1), 02-13. Recuperado: 12 jul. 2012. Disponível: http://pepsic.bvsalud.org/scielo. php?script=sci_arttext\&pid=S1809-52672008000100002\&Ing=pt\&nr $\mathrm{m}=$ iso. 
Lefèbvre, H. (1986). La prodution de l'espace. Paris, Anthropos.

Patto, M. H. S. A. (2001). Produção do Fracasso Escolar: Histórias de Submissão e Rebeldia. São Paulo: Casa do Psicólogo.

Rohde, L., \& Halpern, R. (2004). Transtorno de déficit de atenção/ hiperatividade: atualização. Jornal de Pediatria. Recuperado: 14 fev. 2007. Disponível: http://www.jped.com.br/conteudo/0480-S61/port.asp.

Schmitz, M., Polanczyk, G., \& ROHDE, L. A. P. (2007), v.56, suppl.1 p. 25-29). TDAH: remissão na adolescência e preditores de persistência em adultos. Jornal Brasileiro de Psiquiatria, 56 (Suppl. 1), 25-29. Recuperado: 26 out. 2013. Disponível: http://www.scielo.br/scielo.php?script=sci_arttext \&pid=S0047$20852007000500006 \&$ lng=en\&nrm=iso.
Souza, M. P. R. (2011). Entrevista com Marilda Gonçalves Dias Facci. Psicologia Escolar e Educacional, 15 (1), 173-175.

SOUZA, M. (2004). A experiência da lei e a lei da experiência: ensaios sobre práticas sociais e subjetividades no Brasil. Rio de Janeiro: Revan.

Vasconcelos, M., Malheiros, A. F. A., Werner Jr, J., Brito, A. R., Barbosa, J. B., Santos, I. S. O., \& Lima, D. F. (2005). Contribuição dos fatores de risco psicossociais para o transtorno de déficit de atenção/ hiperatividade. Arquivos de Neuro-Psiquiatria, 63(1), 68-74. Recuperado: 02 fev. 2007. Disponível: http://www.scielo.br/scielo. php? script=sci_arttext\&pid=S0004-282X2005000100013\&lng=en

Recebido em: 30/04/2013

Reformulado em: 08/11/2013

Aprovado em: 31/12/2013

\section{Sobre as autoras}

leda Maria Munhós Benedetti (iedabenedetti@hotmail.com)

Possui doutorado em Educação pela Universidade Federal do Mato Grosso do Sul.

Alexandra Anache (alexandra.anache@gmail.com)

Possui doutorado em Psicologia Escolar e do Desenvolvimento Humano pela Universidade de São Paulo. Professora da Universidade Federal de Mato Grosso do Sul. 